\title{
Co-occurring amphetamine use and associated medical and psychiatric comorbidity among opioid-dependent adults: results from the Clinical Trials Network
}

\author{
This article was published in the following Dove Press journal: \\ Substance Abuse and Rehabilitation \\ 26 July 2011 \\ Number of times this article has been viewed
}

\author{
Daniel J Pilowsky' \\ Li-Tzy Wu ${ }^{2}$ \\ Bruce Burchett ${ }^{2}$ \\ Dan G Blazer ${ }^{2}$ \\ George E Woody ${ }^{3}$ \\ Walter Ling ${ }^{4}$ \\ 'Departments of Epidemiology and \\ Psychiatry, Columbia University, \\ and the New York State Psychiatric \\ Institute, New York City, NY; \\ ${ }^{2}$ Department of Psychiatry and \\ Behavioral Sciences, School of \\ Medicine, Duke University Medical \\ Center, Durham, NC; ${ }^{3}$ Department \\ of Psychiatry, School of Medicine, \\ University of Pennsylvania and \\ Treatment Research Institute, \\ Philadelphia, PA; ${ }^{4}$ David Geffen School \\ of Medicine, NPI/Integrated Substance \\ Abuse Programs, University of \\ California, Los Angeles, CA, USA
}

Correspondence: Daniel J Pilowsky Department of Epidemiology, Mailman School of Public Health, Columbia University, 722 West 168th Street, New York, NY 10032, USA

$\mathrm{Tel}+\mathrm{I} 2123046554$

Fax +l 6463170013

Email dpI4@columbia.edu
Background: In response to the rising rate of treatment admissions related to illicit use of amphetamines (eg, methamphetamine), we examined the prevalence of amphetamine use among treatment-seeking, opioid-dependent adults, explored whether amphetamine users were as likely as nonamphetamine users to enroll in opioid-dependence treatment trials, and determined whether amphetamine users manifested greater levels of medical and psychiatric comorbidity than nonusers.

Methods: The sample included 1257 opioid-dependent adults screened for participation in threemultisite studies of the National Drug Abuse Treatment Clinical Trials Network (CTN001-003), which studied the effectiveness of buprenorphine for opioid detoxification under varying treatment conditions. Patients were recruited from 23 addiction treatment programs across the US. Medical and psychiatric comorbidity were examined by past-month amphetamine use (current vs former) and route of administration. Five mutually exclusive groups were examined, ie, nonusers, current amphetamine injectors, current amphetamine noninjectors, former amphetamine injectors, and former amphetamine noninjectors.

Results: Of the sample $(\mathrm{n}=1257), 22.3 \%$ had a history of regular amphetamine use. Of the 280 amphetamine users, $30.3 \%$ reported injection as their primary route. Amphetamine users were more likely than nonusers to be white and use more substances. Amphetamine users were as likely as nonusers to enroll in treatment trials. Bivariate analyses indicated elevated rates of psychiatric problems (depression, anxiety, hallucinations, cognitive impairment, violence, suicidal thoughts/attempts) and medical illnesses (dermatological, hepatic, cardiovascular, respiratory, neurological, seizure, allergy conditions) among amphetamine users. After adjusting for demographic variables and lifetime use of other substances: current amphetamine users and former injectors showed an increased likelihood of having medical illnesses and hospitalizations; current injectors had elevated odds of suicidal thoughts or attempts; current noninjectors exhibited elevated odds of anxiety, cognitive impairment, and violent behaviors; and former noninjectors had increased odds of depression.

Conclusion: Treatment-seeking, amphetamine-using, opioid-dependent adults manifest greater levels of medical and psychiatric morbidity than treatment-seeking, opioid-dependent adults who have not used amphetamines, indicating a greater need for intensive clinical management.

Keywords: amphetamine use, buprenorphine, clinical trials network, injection drug use, methamphetamine use, opioid dependence, rehabilitation

\section{Introduction}

Amphetamine-associated problems (eg, injecting use, addiction, unprotected sexual behaviors, human immunodeficiency virus [HIV] infection, psychiatric symptoms, 
medical illness, and injuries) constitute an emerging public health concern in the US and elsewhere. ${ }^{1-5}$ While treatment demand for cocaine use problems have been estimated to have decreased, treatment demand for amphetamine use problems has risen in North America. ${ }^{3}$ Several other regions throughout the world have also observed an increased rate of illicit amphetamine use (eg, east and southeast Asia, some European countries, South Africa, New Zealand, and Australia). ${ }^{3,5}$ In the US, methamphetamine is reported to be the primary amphetamine abused, accounting for more than $90 \%$ of amphetamine-related treatment admissions; available data show significant increases in amphetamine-related treatment admissions during the 1990s and 2000s. ${ }^{6}$ Similarly, national surveys of the general US population reveal substantial increases in the number of new methamphetamine users during the 2000s; although the rate declined from 2007-2008, it increased again in $2009 .^{7}$

Increasing rates of illicit amphetamine use and treatment admissions raise concerns about the medical and psychiatric problems associated with its use, particularly among illicit opioid users. ${ }^{8-10}$ Like most drugs of abuse, amphetamines are coabused with other illicit drugs, and psychiatric problems are particularly common among illicit opioid or injection drug users. ${ }^{8-11}$ One pattern of polysubstance use involves using opioids and other substances, such as amphetamines, to reduce negative affect. ${ }^{12}$ Recent findings from the 2001-2002 National Epidemiologic Survey on Alcohol and Related Conditions reveal that illicit opioid users had a greater lifetime prevalence of drug use disorders (including amphetamine use disorders) and mood/anxiety disorders than drug users who did not use illicit opioids. ${ }^{11}$ An increasing number of studies have suggested that amphetamine use poses an additional health risk among illicit opioid users. ${ }^{13-15}$ Findings from injection drug users in the US found that methamphetamine, either used alone or combined with opioids, substantially increased the odds of HIV seropositivity, and that this association remained significant after adjusting for other substance use and HIV risk behaviors. ${ }^{8}$

In addition to posing a high risk for HIV infection, using unsterile injection equipment or engaging in unprotected sex, amphetamine-related intoxication and toxicity is associated with acute and chronic medical problems affecting multiple organ systems (eg, dermatological, cardiovascular, respiratory, gastrointestinal, genitourinary, neurological, dental), and includes death from accidents, cerebrovascular hemorrhage, or cardiac arrest. ${ }^{16-22}$ Amphetamine use also confers a heightened risk for a wide range of psychiatric problems that include depression, suicidal ideation or attempts, anxiety, impulsivity, cognitive deficits, aggressive behaviors, ${ }^{9,24-29}$ and a clinical syndrome that resembles schizophrenia. ${ }^{12,21,22}$ For example, McKetin et al found that the prevalence of psychosis among current methamphetamine users was eleven times higher than the rate in the general population. ${ }^{23}$

Taken together, data from many sources show that amphetamine use is growing in the US and elsewhere, and that it is a significant public health problem. To date, epidemiological research on amphetamine users has focused primarily on HIV-related risk, and there has been less focus on more comprehensive patterns of medical and psychiatric conditions that are likely to be found in treatment-seeking individuals who have used amphetamines. ${ }^{15,16}$ Nonetheless, a better understanding of amphetamine use and its associated medical and psychiatric comorbidities could alert clinicians to the special problems that are highly prevalent in these patients and often require clinical attention. Of note, amphetamine use among opioid-addicted patients and the availability of office-based opioid dependence treatments are an opportunity to engage more of these patients in care and address their personal, medical, and social problems. ${ }^{30,31}$ In this regard, three multisite opioid dependence treatment trials from the National Drug Abuse Treatment Clinical Trials Network (CTN) provide an opportunity to explore the extent of illicit amphetamine use and its associated harms in a large sample of opioid-dependent adults recruited from 23 addiction treatment programs across the US, and alert clinicians to problems they are likely to encounter when treating these patients..$^{32,33}$

To this end, this study had three aims: to determine the prevalence and demographic profiles of illicit amphetamine use among treatment seeking opioid-dependent patients and explore whether they are as likely as nonamphetamine users to enroll in opioid addiction treatment trials testing the effectiveness of buprenorphine therapy:32,33 to examine whether opioid-dependent individuals with amphetamine use have a more pervasive pattern of medical illnesses and hospitalization than opioid-dependent individuals without amphetamine use; and to determine whether opioid-dependent individuals using amphetamine have more psychiatric problems than opioid-dependent individuals not using amphetamine. The CTN data from the three studies that were used for these analyses are well suited for this work, because they include information about concurrent substance use, and medical and psychopathological symptoms from a large number of opioid-dependent individuals shortly after they enrolled in inpatient and outpatient treatment settings at various sites across the country. ${ }^{33-37}$ 


\section{Methods}

\section{Data source}

Data were from the CTN, initiated in 1999 with the stated purpose of facilitating the translation of science-based treatments for addictive disorders into community-based treatment settings. ${ }^{33}$ The CTN includes 13 nodes based in research centers allied with substance abuse treatment providers in 39 states across the US, the District of Columbia, and Puerto Rico (a map showing the location of clinical sites is available in Tai et $\mathrm{a}^{33}$ ). For this study, the intake data from all screened individuals who met Diagnostic and Statistical Manual, Version IV (DSM-IV) criteria for opioid dependence in three CTN studies were included in the analysis. Two of these studies (CTN 001 and 002) compared buprenorphine/ naloxone with clonidine for detoxification in inpatient and outpatient settings, ${ }^{33-36}$ the third study (CTN003) compared two buprenorphine/naloxone taper schedules. ${ }^{37}$ The sample for these studies included 1257 randomized and nonrandomized opioid-dependent adults, ie, 126 in CTN 001, 251 in CTN 002, and 880 in CTN 003. Opioid-dependent adults who did not meet the eligibility criteria and were not randomized were included in the analysis, which enabled us to ascertain whether amphetamine users are disproportionately excluded from addiction treatment trials and provides a larger sample for examining differences in medical and psychiatric conditions between current (past-month) and former (prior to past month) amphetamine users compared with nonusers. Nonrandomized individuals were assessed for all study variables, and all met DSM-IV criteria for opioid dependence. The Duke University institutional review board approved use of these data for this study.

\section{Eligibility for CTN $00 \mathrm{I}$ and 002}

Inpatients were recruited from six programs located in eastern, southeastern, midwestern, or western regions of the US (CTN 001), and outpatients were recruited from six programs located in eastern, midwestern, or western regions of the US (CTN 002). Patients were recruited by word of mouth, referrals from local narcotic treatment and outreach programs, outpatient and inpatient alcohol and drug abuse clinics, primary care physicians, local mental health centers and crisis clinics, public service announcements, newspaper advertisements, and hospital emergency rooms. Recruitment advertisements were approved by each site's institutional review board. Eligible patients included treatment-seeking adults aged 18 years or older who met the DSM-IV criteria for opioid dependence and were in need of medical management for opioid withdrawal. ${ }^{33-36}$ Patients were excluded if they had a serious psychiatric or medical condition that would make participation medically hazardous, had a known allergy or sensitivity to buprenorphine, naloxone, or clonidine, were receiving medications contraindicated with clonidine, or had a systolic blood pressure $<100 \mathrm{mmHg}$ or pulse $<56$ beats per minute, had been enrolled in a methadone treatment program or had participated in another investigational drug study within 30 days of study enrollment, or could not remain in the area for the duration of active treatment. Dependence on other drugs did not exclude individuals from participation unless they required immediate medical attention to manage these disorders. Females were excluded if pregnant or lactating, and were required to have a negative pregnancy test prior to randomization.

\section{Eligibility for CTN 003}

Eligible participants were at least 15 years of age and seeking treatment for opioid dependence at one of eleven participating treatment programs in ten US cities (located in Colorado, Washington, Oregon, Connecticut, New York, Virginia, and North Carolina).${ }^{37}$ Recruitment methods included word of mouth, radio announcements, newspaper advertisements, and referrals from local opioid treatment and outreach programs, alcohol and drug abuse clinics, primary care providers, local mental health centers, crisis clinics, and hospital emergency rooms. Participants were excluded if they provided a urine sample testing positive for methadone or benzodiazepine, were in poor general health, had a self-reported allergy to buprenorphine or naloxone, were pregnant or nursing, had a medical or psychiatric condition that could make participation unsafe, were dependent on alcohol or any drug other than opioids (per DSM-IV criteria), or had participated in any investigational drug study or methadone maintenance or detoxification in the previous 30 days. Pending legal action and inability to remain in the area also precluded participation. Females of childbearing potential could participate if they agreed to use an acceptable form of birth control.

\section{Study variables}

\section{Demographic variables}

Age, gender, race/ethnicity (non-Hispanic, white, nonHispanic black, Hispanic, other), years of education, marital status, and current employment status.

\section{Substance use}

Substance use variables were assessed by the Addiction Severity Index, ${ }^{38,39}$ that included past 30 days use, route of administration (injecting vs noninjecting), and lifetime regular use 
of amphetamines (including methamphetamine). To explore if route of use influences health status, amphetamine users are dichotomized into injecting users vs noninjecting users.

The amphetamine data were used to categorize subjects into five mutually exclusive groups, ie, nonamphetamine users, current amphetamine injectors, current amphetamine noninjectors, former amphetamine injectors, and former amphetamine noninjectors. Former use referred to use prior to the past 30 days. A number representing other substances that were used regularly during the patient's lifetime was created by summing the lifetime use of all other substance classes (alcohol, sedatives/tranquilizers, cocaine/crack, cannabis, hallucinogens, inhalants, nicotine/tobacco) and included in the adjusted model to control for its potentially confounding effect on the association between amphetamine use and health status. ${ }^{16}$ Regular use of any substance, including amphetamines, was defined as using three or more times per week.

\section{Medical status}

We used the Addiction Severity Index medical status section to ascertain current medical problems ("Do you have any chronic medical problems that continue to interfere with your life?") and the number of lifetime medical hospitalizations ("How many times in your life have you been hospitalized for medical problems?"). Additionally, data from the CTN medical history form, ie, a checklist of 14 categories of medical illness (dermatological, cardiovascular, eyes/ears/nose/throat, respiratory, tuberculosis, musculoskeletal, gastrointestinal, hepatitis, genitourinary, endocrine, psychiatric, neurological, seizure, allergies) that were assessed and evaluated by medical personnel, were used to identify the number of lifetime medical illnesses affecting specific organ systems.

\section{Psychiatric symptoms}

The Addiction Severity Index psychiatric status section was used to determine the presence of current (past 30 days) psychiatric symptoms, including depression, anxiety, hallucinations, cognitive impairment, violence, suicidal thoughts or attempts, and psychotropic medication use. ${ }^{16}$ For example, individuals were considered to have current symptoms of depression if they answered affirmatively to the following Addiction Severity Index question in reference to the preceding 30 days: "Have you had a significant period of time (that was not the direct result of drug or alcohol use) in which you experienced serious depression - sadness, hopelessness, loss of interest, difficulty with daily function?" Similarly phrased questions were used to ascertain the presence of other psychiatric conditions.

\section{Data analysis}

Bivariate associations of each study variable with amphetamine use status were determined using the $\chi^{2}$ test for proportions and $t$-test for continuous variables. To reduce the chance of false positive associations, only variables associated with amphetamine use status $(P \leq 0.05)$ from bivariate analyses were examined in the adjusted analysis. We performed adjusted logistic regression procedures for categorical variables and linear regression procedures for continuous variables to estimate the strength of association between amphetamine use status and health status (medical and psychiatric variables, respectively). We report adjusted odds ratios (AOR) from the models controlling for potential confounding influences from age, gender, race/ethnicity, years of education, and employment status, as well as AOR controlling for the lifetime number of other substance classes used. The latter explored whether the association between amphetamine use and health status was influenced by other substance use. Data analyses were conducted by SAS (version 9.2; SAS Institute, Cary, NC). ${ }^{40}$

\section{Results \\ Prevalence of amphetamine use among opioid-dependent adults}

Of all opioid-dependent adults aged 18 years or above $(\mathrm{n}=1257), 22 \%$ had a history of regular amphetamine use: current amphetamine injectors, $2.8 \%$; current amphetamine noninjectors, $6.2 \%$; former injectors, $4.0 \%$; and former noninjectors, 9.3\%. Overall, 68\% of those who were assessed were randomized, and amphetamine users were as likely as nonusers to be randomized.

\section{Demographic and substance use characteristics}

Compared with nonusers (Table 1), current amphetamine noninjectors were more likely to be female (30\% vs $50 \%$, $P<0.001)$, and a similar gender effect was seen in former noninjectors ( $30 \%$ vs $41 \%, P<0.05)$. Compared with nonusers (57\%), all four groups of amphetamine users were more likely to be white $(74 \%-83 \%, P<0.05)$ and to use more substances in their lifetime. A higher proportion of current amphetamine noninjectors were not employed compared with nonusers $(62 \%$ vs $50 \%, P<0.05)$.

\section{Prevalence of medical problems}

As shown in Table 2, former amphetamine users had a higher prevalence of current medical problems that they reported as 
Table I Demographic and substance use characteristics of opioid-dependent adults according to amphetamine use status $(\mathrm{n}=1257)$

\begin{tabular}{|c|c|c|c|c|c|}
\hline Proportion, \% & $\begin{array}{l}\text { Nonamphetamine } \\
\text { users }\end{array}$ & $\begin{array}{l}\text { Current } \\
\text { amphetamine } \\
\text { injectors }^{\mathrm{a}} \\
\end{array}$ & $\begin{array}{l}\text { Current } \\
\text { amphetamine } \\
\text { noninjectors }^{\mathrm{a}} \\
\end{array}$ & $\begin{array}{l}\text { Former } \\
\text { amphetamine } \\
\text { injectors }^{\mathrm{a}} \\
\end{array}$ & $\begin{array}{l}\text { Former } \\
\text { amphetamine } \\
\text { noninjectors }^{\mathrm{a}} \\
\end{array}$ \\
\hline Sample size & $\mathrm{n}=977$ & $\mathrm{n}=\mathbf{3 5}$ & $n=78$ & $\mathbf{n}=\mathbf{5 0}$ & $n=117$ \\
\hline Age in years, mean (SD) ${ }^{b}$ & $36.4(0.34)$ & $34.4(1.50)$ & $36.1(1.17)$ & $38.2(1.38)$ & $36.5(0.89)$ \\
\hline \multicolumn{6}{|l|}{ Gender } \\
\hline Male & 69.9 & 57.1 & $50.0 * *$ & 70.0 & $59.0 *$ \\
\hline Female & 30.1 & 42.9 & 50.0 & 30.0 & 41.0 \\
\hline \multicolumn{6}{|l|}{ Race/ethnicity } \\
\hline Nonwhite & 43.5 & $25.7^{*}$ & $18.0 * *$ & $20.0 * *$ & $17 .\left.\right|^{* *}$ \\
\hline White & 56.5 & 74.3 & 82.0 & 80.0 & 82.9 \\
\hline \multicolumn{6}{|l|}{ Education, years } \\
\hline $0-12$ & 56.4 & 54.3 & 50.0 & 64.0 & 50.4 \\
\hline $13+$ & 43.6 & 45.7 & 50.0 & 36.0 & 49.6 \\
\hline \multicolumn{6}{|l|}{ Marital status } \\
\hline Married & 27.4 & 34.3 & 35.9 & 24.0 & 33.3 \\
\hline Separated/divorced/widowed & 25.6 & 14.3 & 25.6 & 32.0 & 26.5 \\
\hline Never married & 47.0 & 51.4 & 38.5 & 44.0 & 40.2 \\
\hline \multicolumn{6}{|l|}{ Employment, past month } \\
\hline Not employed & 50.0 & 60.0 & $61.5^{*}$ & 52.0 & 51.3 \\
\hline Employed & 50.1 & 40.0 & 38.5 & 48.0 & 48.7 \\
\hline \multicolumn{6}{|l|}{ Randomization } \\
\hline No & 31.5 & 34.3 & 32.1 & 34.0 & 36.8 \\
\hline Yes & 68.5 & 65.7 & 68.0 & 66.0 & 63.3 \\
\hline $\begin{array}{l}\text { Number of other substances } \\
\text { used regularly, lifetime, } \\
\text { mean (SD) }\end{array}$ & $3.00(1.42)$ & $3.91(1.27)^{* *}$ & $3.4 \mathrm{I}(\mathrm{I} .42)^{*}$ & $4.34(\mathrm{I} .33)^{* *}$ & $4.10(1.44)^{* *}$ \\
\hline
\end{tabular}

Notes: ${ }^{a}$ Each amphetamine use group was compared with nonamphetamine users; ${ }^{b} t$-tests for age were not significant. $* P \leq 0.05$; $* * P \leq 0.0$ I. Abbreviation: SD, standard deviation.

Table 2 Prevalence of specific medical conditions by amphetamine use status among opioid-dependent adults aged 18 years or older $(\mathrm{n}=1257)$

\begin{tabular}{|c|c|c|c|c|c|}
\hline $\begin{array}{l}\text { Proportion of } \\
\text { medical illness, \% }\end{array}$ & $\begin{array}{l}\text { Nonamphetamine } \\
\text { users }\end{array}$ & $\begin{array}{l}\text { Current } \\
\text { amphetamine } \\
\text { injectors }^{\text {b }}\end{array}$ & $\begin{array}{l}\text { Current } \\
\text { amphetamine } \\
\text { noninjectors }^{\mathrm{b}}\end{array}$ & $\begin{array}{l}\text { Former } \\
\text { amphetamine } \\
\text { injectors }^{\text {b }}\end{array}$ & $\begin{array}{l}\text { Former } \\
\text { amphetamine } \\
\text { noninjectors }^{b}\end{array}$ \\
\hline Sample size & $n=977$ & $n=35$ & $n=78$ & $\mathbf{n}=\mathbf{5 0}$ & $n=117$ \\
\hline $\begin{array}{l}\text { Current chronic medical problems } \\
\text { that continue to interfere with life }\end{array}$ & 25.4 & 37.1 & 30.8 & $44.0 * *$ & $34.2^{*}$ \\
\hline Dermatological illness ${ }^{\mathrm{a}}$ & 22.8 & $60.0 * *$ & $38.5^{* *}$ & $60.0 * *$ & $37.6 * *$ \\
\hline Psychiatric illness $^{\mathrm{a}}$ & 27.9 & $51.4 * *$ & $42.3 * *$ & $42.0^{*}$ & $41.9 * *$ \\
\hline Hepatitis $^{\mathrm{a}}$ & 22.3 & $48.6 * *$ & $35.9 * *$ & $54.0 * *$ & I7.I \\
\hline Allergies $^{\mathrm{a}}$ & 21.9 & 31.4 & $34.6 * *$ & $34.0^{*}$ & $29.1^{\ddagger}$ \\
\hline Respiratory illness ${ }^{\mathrm{a}}$ & 17.0 & $31.4 *$ & $29.5 * *$ & $28.0 *$ & 19.7 \\
\hline Seizure $^{\mathrm{a}}$ & 3.8 & $14.3 * *$ & $7.7^{\ddagger}$ & $12.0 * *$ & $7.7^{*}$ \\
\hline Gastrointestinal illness $^{a}$ & 19.2 & 22.9 & $29.5^{*}$ & 24.0 & 25.6 \\
\hline Cardiovascular illness $^{\mathrm{a}}$ & 17.7 & 14.3 & $23.1^{\ddagger}$ & 26.0 & 20.5 \\
\hline Genitourinary illness ${ }^{\mathrm{a}}$ & 12.5 & 20.0 & $20.5^{*}$ & $22.0^{*}$ & $18.0^{\ddagger}$ \\
\hline Neurological illness $^{\mathrm{a}}$ & 11.0 & 14.3 & 14.1 & $32.0 * *$ & 8.5 \\
\hline Musculoskeletal illness ${ }^{a}$ & 28.9 & 34.3 & 34.6 & 34.0 & 32.5 \\
\hline Eye, ear, nose, or throat illness ${ }^{\mathrm{a}}$ & 13.1 & 17.1 & 20.5 & 14.0 & 10.3 \\
\hline Tuberculosis $^{\mathrm{a}}$ & 8.7 & 5.7 & 6.4 & 10.0 & 4.3 \\
\hline Endocrine illness ${ }^{\mathrm{a}}$ & 4.0 & 0 & 1.3 & 8.0 & 6.8 \\
\hline
\end{tabular}

Notes: aLifetime status; beach amphetamine use group was compared with nonamphetamine users. Chi-square test: ${ }^{\ddagger} P<0.10$; $* P \leq 0.05 ; * * P \leq 0.01$. 
interfering with their lives (44\% among injectors; $34 \%$ among noninjectors) than nonusers $(25 \%)$. Of the 14 categories of medical illness examined, dermatological, psychiatric, hepatitis, allergies, respiratory, and musculoskeletal conditions were the most common problems, and all four groups of amphetamine users had higher rates of dermatological (38\%-60\% vs $23 \%)$, psychiatric $(42 \%-51 \%$ vs $28 \%)$, and seizure $(8 \%-14 \%$ vs $4 \%)$ problems than nonusers. Current and former injectors had a much higher rate than nonusers of hepatitis ( $49 \%-54 \%$ vs $22 \%)$; current noninjectors and former injectors had a higher rate of allergies $(34 \%-35 \%$ vs $22 \%$ ), respiratory illnesses ( $28 \%-30 \%$ vs $17 \%$ ), and genitourinary conditions $(21 \%-22 \%$ vs $13 \%)$ than nonusers, and current amphetamine injectors also had a higher prevalence than nonusers of respiratory illnesses ( $31 \%$ vs $17 \%)$.

\section{Adjusted analyses of medical problems}

After adjusting for potential confounders (age, gender, race/ethnicity, education, employment status, and lifetime number of other substances used), the most salient difference between amphetamine users and nonusers was related to dermatological problems and hepatitis (Table 3). All groups of amphetamine users had elevated odds of dermatological conditions compared with nonusers; current $(\mathrm{AOR}=4.7,95 \%$ confidence interval $[\mathrm{CI}]: 2.3-9.5)$ and former $(\mathrm{AOR}=4.7,95 \% \mathrm{CI}: 2.6-8.6)$ injectors were close to five times more likely than nonusers to have a dermatological problem. Compared with nonusers, there was an excess of hepatitis (AOR ranging from 2.0 to 3.9) among amphetamine users, with the exception of former noninjectors. There were elevated odds of psychiatric illness $(\mathrm{AOR}=2.2,95 \% \mathrm{CI}: 1.1-4.5)$ and seizures $(\mathrm{AOR}=3.3$, 95\% CI: 1.2-9.5) among current injectors; a slight increase in the odds of respiratory $(\mathrm{AOR}=1.9,95 \% \mathrm{CI}: 1.1-3.2)$ and cardiovascular $(\mathrm{AOR}=1.9,95 \% \mathrm{CI}$ : 1.0-3.5) illnesses among current amphetamine noninjectors; increased odds of allergies among current noninjectors ( $\mathrm{AOR}=1.7,95 \%$ CI: $1.1-2.9)$ and former injectors $(\mathrm{AOR}=1.9,95 \% \mathrm{CI}$ : 1.1-3.5); and elevated odds of neurological conditions $(\mathrm{AOR}=3.6,95 \% \mathrm{CI}: 1.8-7.0)$ among former injectors. In addition, former injectors showed greater odds than nonusers of having current chronic medical problems; the association of gastrointestinal and genitourinary conditions with amphetamine use became nonsignificant in the adjusted analysis.

While summarizing all available medical illnesses as an aggregate variable (Table 4), current amphetamine users (regardless of route of use) and former injectors had a greater

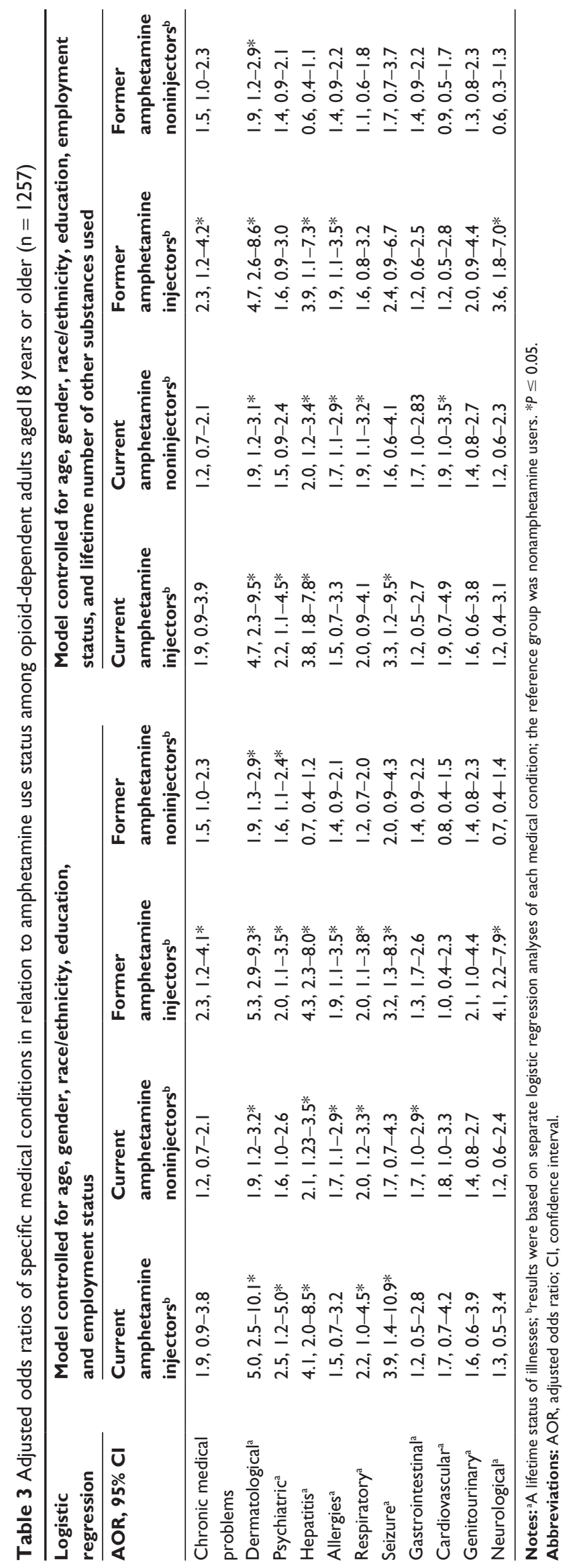


Table 4 Lifetime number of medical conditions and hospitalizations in relation to amphetamine use status among opioid-dependent adults aged 18 years or older $(n=1257)$

\begin{tabular}{|c|c|c|c|c|c|}
\hline Mean (SD) & $\begin{array}{l}\text { Nonamphetamine } \\
\text { users }\end{array}$ & $\begin{array}{l}\text { Current } \\
\text { amphetamine } \\
\text { injectors }^{\mathrm{b}}\end{array}$ & $\begin{array}{l}\text { Current } \\
\text { amphetamine } \\
\text { noninjectors }^{\mathrm{b}}\end{array}$ & $\begin{array}{l}\text { Former } \\
\text { amphetamine } \\
\text { injectors }^{\mathrm{b}}\end{array}$ & $\begin{array}{l}\text { Former } \\
\text { amphetamine } \\
\text { noninjectors }^{\mathrm{b}} \\
\end{array}$ \\
\hline Sample size & $n=977$ & $\mathrm{n}=\mathbf{3 5}$ & $n=78$ & $\mathbf{n}=\mathbf{5 0}$ & $n=117$ \\
\hline $\begin{array}{l}\text { Number of medical } \\
\text { illnesses in the lifetime }\end{array}$ & $2.2(2.02)$ & $3.3(2.4 \mathrm{I})^{* *}$ & $3.2(2.34)^{* *}$ & $3.4(2.63)^{* *}$ & $2.5(1.96)$ \\
\hline $\begin{array}{l}\text { Number of hospitalizations } \\
\text { in the lifetime }\end{array}$ & $1.7(2.60)$ & $3.3(3.06) * *$ & $2.2(2.91)$ & $3.0(3.2 I)^{* *}$ & $2.1(2.42)$ \\
\hline
\end{tabular}

Notes: aThe number of medical conditions in the lifetime included the 14 categories of illness listed in Table 2 except for current chronic health problems; ${ }^{\text {beach amphetamine }}$ use group was compared with nonamphetamine users. $t$-test: $* * p<0.01$.

Abbreviation: SD, standard deviation.

number of illnesses than nonusers, and current and former amphetamine-injecting users had a greater number of hospitalizations in their lifetime than nonusers. These associations remained significant in the adjusted linear regression analysis controlling for the aforementioned potential confounders (data not shown).

\section{Prevalence of current psychiatric problems}

Anxiety and depression were comparatively prevalent in the overall sample (Table 5), and the two current amphetamine use groups were more likely than nonusers to be on prescribed psychotropic medication (18\%-20\% vs 10\%). Compared with nonusers, current amphetamine noninjectors reported a higher rate of anxiety ( $58 \%$ vs 36\%) and cognitive impairment (38\% vs 24\%); former noninjectors reported a higher rate of depression (39\% vs 29\%) and cognitive impairment (33\% vs 24\%). Additionally, current amphetamine injectors showed a higher rate of violent behaviors $(17 \%$ vs $6 \%)$ and suicidal thoughts/attempts ( $11 \%$ vs $4 \%$ ) than nonusers; current amphetamine noninjectors also showed a higher rate of violent behaviors (13\% vs 6\%) and hallucinations (6\% vs $2 \%$ ) than nonusers.

\section{Adjusted analyses of current psychiatric problems}

After controlling for the aforementioned potential confounders (Table 6), former noninjectors remained more likely than nonusers to have symptoms of depression in the past 30 days $(\mathrm{AOR}=1.6,95 \% \mathrm{CI}$ : 1.1-2.4). Additionally, current noninjectors had greater odds than nonusers of having anxiety $(\mathrm{AOR}=1.9,95 \% \mathrm{CI}: 1.2-3.1)$, cognitive impairment $(\mathrm{AOR}=1.6,95 \% \mathrm{CI}: 1.0-2.7)$, and violent behaviors $(\mathrm{AOR}=2.1,95 \% \mathrm{CI}: 1.0-4.5)$; current injectors had greater odds than nonusers of having suicidal thoughts/attempts $(\mathrm{AOR}=3.1,95 \% \mathrm{CI}: 1.0-9.8)$.

\section{Discussion}

In this large and geographically diverse sample of treatmentseeking opioid-dependent adults, slightly more than one fifth $(22 \%)$ had a history of regular amphetamine use; of all amphetamine users, 30\% reported injection as their primary route. Amphetamine users were more likely than nonusers to be white and use more substances. After controlling for the lifetime number of other substances used and sociodemographic characteristics, amphetamine users still manifested a greater level of medical illnesses (current

Table 5 Current psychiatric status ${ }^{\mathrm{a}}$ by amphetamine use status among opioid-dependent adults aged 18 years or older $(\mathrm{n}=1257)$

\begin{tabular}{|c|c|c|c|c|c|}
\hline Psychiatric status, \% & $\begin{array}{l}\text { Nonamphetamine } \\
\text { users }\end{array}$ & $\begin{array}{l}\text { Current } \\
\text { amphetamine } \\
\text { injectors }^{b}\end{array}$ & $\begin{array}{l}\text { Current } \\
\text { amphetamine } \\
\text { noninjectors }^{b}\end{array}$ & $\begin{array}{l}\text { Former } \\
\text { amphetamine } \\
\text { injectors }^{b}\end{array}$ & $\begin{array}{l}\text { Former } \\
\text { amphetamine } \\
\text { noninjectors }^{b}\end{array}$ \\
\hline Sample size & $\mathbf{n}=977$ & $n=35$ & $\mathbf{n}=\mathbf{7 8}$ & $\mathbf{n}=\mathbf{5 0}$ & $\mathbf{n}=|| \mathbf{7}$ \\
\hline Anxiety & 36.3 & 48.6 & $55.7 * *$ & 47.1 & $44.4^{\ddagger}$ \\
\hline Depression & 28.9 & 40.0 & 38.0 & 31.4 & $38.5^{*}$ \\
\hline Cognitive impairment & 24.3 & 25.7 & $38.0 * *$ & 22.0 & $33.3^{*}$ \\
\hline Violent behaviors & 6.2 & $17 .\left.\right|^{* *}$ & $12.7^{*}$ & 7.8 & $10.3^{\ddagger}$ \\
\hline Suicidal thoughts or attempts & 3.5 & $11.4 *$ & 2.5 & 5.9 & 5.1 \\
\hline Hallucinations & 2.0 & 5.7 & $6.3^{*}$ & 3.9 & 0.9 \\
\hline Psychotropic medication treatment & 9.6 & $20.0^{*}$ & $17.7 *$ & 5.9 & 12.8 \\
\hline
\end{tabular}

Notes: aPast 30 days; beach amphetamine use group was compared with nonamphetamine users. Chi-square test $(\mathrm{df}=1)$ : ${ }^{\ddagger} P<0.10 ; * P \leq 0.05 ; * * P \leq 0.01$. 


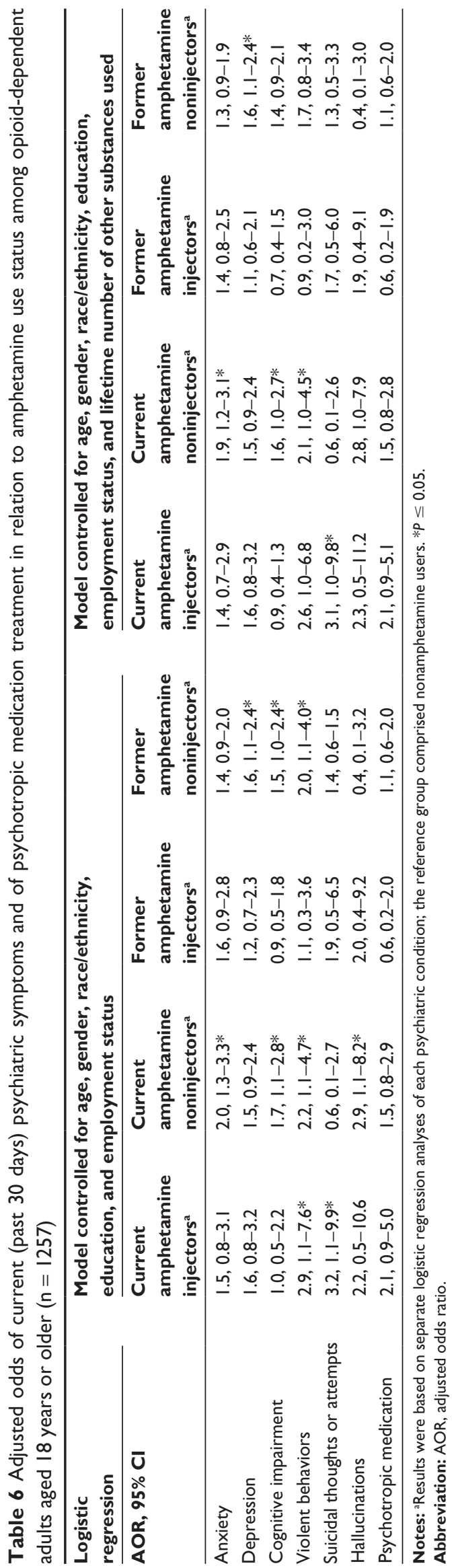

amphetamine users and former injectors), hospitalizations (injectors), and psychiatric problems (current amphetamine users). These results provide clinical evidence that treatmentseeking, opioid-dependent adults who use amphetamines have poorer medical and psychological health than their counterparts who did not use amphetamines. These patients thus warrant additional clinical assessments and interventions to facilitate treatment engagement and deliver coordinated care for comorbid conditions. The association between white ethnicity and amphetamine use is consistent with other studies of treatment-seeking drug users. ${ }^{41,42}$ However, we found a higher rate of amphetamine-injecting use than the estimate from the US Treatment Episode Data Set, which found that $18 \%$ of treatment-seeking amphetamine users reported injection as their primary route of use. ${ }^{41}$ This discrepancy may be related to the severity of dependency in our study participants, given that all met criteria for opioid/heroin dependence.

\section{Medical status}

Although current and former amphetamine users showed more lifetime medical problems than nonusers, the associations among former amphetamine users became less consistent in the adjusted analysis, suggesting more medical problems associated with drug use among current users. The most consistent difference in medical conditions was that current and past amphetamine injectors reported more dermatological illnesses than nonusers. Similarly, previous reports have suggested that drug users' use of contaminated needles or injection without disinfecting the surrounding skin is associated with abscesses, cellulitis, and other skin infections, such as methicillin-resistant Staphylococcus aureus (MRSA) skin infections. ${ }^{43-45}$ We also found an elevated prevalence of dermatological illnesses among noninjecting amphetamine users, a finding that is not often reported in the literature. However, a case control study that determined risk factors for MRSA among residents in a rural southeastern community in the US reported a high prevalence of MRSA in a sample of methamphetamine users that included mostly noninjectors. ${ }^{46}$ Factors suggested to be associated with skin infections among amphetamine users include living with someone with a skin infection, skin picking (eg, methamphetamine use is associated with formication, a feeling or sensation that something is crawling on or under the skin, leading in some cases to skin picking), and social factors such as poor hygiene and homelessness, both of which are associated with MRSA skin infections. ${ }^{46}$ Last, amphetamine use is often associated with increased 
sexual activity, and there is a possibility of passing MRSA infections through heterosexual transmission. ${ }^{47}$

In addition, the results revealed an elevated rate of allergies among current amphetamine noninjectors and former injectors, which may be related to underlying immune dysregulation associated with drug abuse. ${ }^{16}$ The finding of a high rate of hepatitis among current and former amphetamine injectors can be a consequence of using contaminated needles or sharing injecting equipment (eg, sharing rinse water and cotton). ${ }^{48-50}$ However, the results also indicate an elevated rate of hepatitis among current amphetamine noninjectors (those using oral or smoked amphetamines) as compared with nonusers. The reason for this finding is not entirely clear; nonetheless, methamphetamine is not always injected and methamphetamine users have a high risk for hepatitis A through multiple routes of transmission (eg, fecal-oral, percutaneous routes, poor hygiene).$^{51}$

Further, current amphetamine users and former injectors had more respiratory conditions than nonusers; after adjusting for potential confounders, only current amphetamine noninjectors showed elevated odds of these conditions. Injection drug use is infrequently associated with foreign body emboli that may affect respiratory function, ${ }^{52}$ although amphetamine users in general used more drugs in their lifetime and often used via multiple routes. For example, they might have inhaled or injected amphetamines and also smoked crack cocaine, a known cause of respiratory problems. ${ }^{53}$ Furthermore, cardiovascular conditions were slightly more prevalent among current amphetamine noninjectors, even after adjustment for potential confounders, a finding previously reported..$^{53}$ Last, the prevalence of seizures and neurological conditions was elevated among current and former injectors, which could be related to neurotoxicity associated with repeated drug use (including methamphetamine). ${ }^{16,53}$

\section{Psychiatric status}

There were few differences in psychiatric variables between former amphetamine users and nonusers. Although current injectors had more symptoms of depression ( $40 \%$ vs $29 \%$ ) and anxiety ( $49 \%$ vs $36 \%$ ) than nonusers, the differences were not statistically significant. This finding might be related to the sample size of amphetamine users, as it had only 35 current injectors. Nonetheless, current injectors reported more suicidal thoughts/attempts (a strikingly high prevalence of over $10 \%$ ) than nonusers, and this difference remained significant after adjusting for demographics and other substance use. Current amphetamine noninjectors also showed elevated odds of having anxiety symptoms in the adjusted analysis, a finding that may be explained by activation of the sympathetic nervous system as a result of alpha receptor stimulation. . $^{16,54,55}$ Overall, these results reveal a high prevalence of depression, anxiety, and suicidal thoughts/attempts among current amphetamine users. ${ }^{9,24,54}$

While a higher prevalence of hallucinations among current amphetamine noninjectors than nonusers is consistent with other research, ${ }^{21,22}$ it did not remain significant after adjustment for multiple confounders, perhaps due to statistical adjustment for the number of other substances used. ${ }^{54}$ Further, violent behavior was evident among current amphetamine users. Zweben et al found that over $40 \%$ of amphetamine users in their sample exhibited aggressive behaviors, ${ }^{24}$ and another study suggested that assaults may be more frequent while amphetamine users are intoxicated..$^{56}$ Last, results indicate elevated odds of cognitive impairment among current amphetamine noninjectors, as suggested by prior research. ${ }^{9}$

\section{Limitations and strengths}

The findings reported here are based on treatment-seeking, opioid-dependent adults who attended community-based treatment programs affiliated with the CTN and may not be applicable to those not seeking treatment. In addition, results of substance use and psychiatric status are based on participants' self-reports, which may be influenced by memory errors and under-reporting (eg, social desirability bias). Last, limited statistical power to detect differences between various groups of amphetamine users and nonusers may constrain our ability to detect differences in health status (eg, further classifying amphetamine users by heroin injecting status).

The study also has important strengths. The data are from three national multisite studies with significant geographical diversity and rigorous methodology. ${ }^{33}$ The results are based on all participants irrespective of study enrollment status. This study also included one of the largest available samples of treatment-seeking, opioid-dependent individuals. The large number of participants enabled us to control for potential confounders, such as number of other substances used during the individual's lifetime. For example, after controlling for demographic variables, hallucinations remained associated with current amphetamine noninjection use, but the finding was no longer significant after controlling for lifetime number of other substances used, thus suggesting the influences of other substance use on hallucinations. 


\section{Clinical and public health implications}

Drug use is seldom limited to a single illicit drug. While there is extensive knowledge about the medical and psychiatric effects of most illicit drugs considered in isolation, less is known about the effects of common combinations of drugs. The coabuse of opioids and amphetamines raises the question of amphetamine effects above and beyond opioid effects. For example, this study showed an excess of dermatological conditions among opioid-dependent adults who also used amphetamines. Although there are a few reports of dermatological infections (eg, MRSA) among amphetamine noninjectors, a high prevalence of dermatological problems has not been well described. Furthermore, while an excess of hepatitis among injectors is not surprising, the high prevalence of hepatitis among amphetamine noninjectors, although known, also represents a significant public health problem that has received limited research attention and has important clinical implications. For example, amphetamine users may benefit from routine screening for hepatitis and hepatitis vaccination..$^{51,57}$

\section{Conclusion}

Treatment-seeking, opioid-dependent adults who have used amphetamines have greater levels of medical and psychiatric morbidity than their counterparts who have not used amphetamines, indicating a greater need for intensive clinical management to optimize treatment outcomes, and preventive measures such as HIV risk reduction counseling and vaccination to prevent hepatitis $\mathrm{A}$ and $\mathrm{B}$ infection. Current amphetamine users may often need psychiatric treatment for depression/anxiety problems, in addition to addiction-focused therapies. The increased access to officebased opioid dependence treatment can serve as a window of opportunity for improving the care of opioid addicted patients with amphetamine problems through application of infectious disease preventive measures and effective referrals or linkage with coordinated services.

\section{Acknowledgments}

Data analysis and preparation of this paper was supported primarily by R21DA027503, R33DA027503, R01DA019623, and R01DA019901 (LT Wu) from the US National Institute on Drug Abuse of the National Institutes of Health, and in part by U10 DA013045 (W Ling), HHSN271200522071C (DG Blazer), and K05DA017009, U10DA013043 (GE Woody). The sponsoring agency had no further role in the study design and analysis, the writing of the report, or the decision to submit the paper for publication. The opinions expressed in this paper are solely those of the authors. The authors thank the study participants, as well as CTN staff and investigators who contributed to the original studies. We thank Amanda McMillan for her editorial assistance.

\section{Disclosure}

WL has received research funding from Titan Pharmaceuticals, Reckitt Benckiser, and Hythiam, and has served as a member of the advisory board for US World Meds. GEW is a member of the RADARS (Researched Abuse, Diversion and Addiction-Related Surveillance) postmarketing study scientific advisory group assessing abuse of prescription medications. Denver Health administers RADARS, and pharmaceutical companies support its work.

\section{References}

1. Maxwell JC, Rutkowski BA. The prevalence of methamphetamine and amphetamine abuse in North America: a review of the indicators, 1992-2007. Drug Alcohol Rev. 2008;27(3):229-235.

2. Corsi KF, Booth RE. HIV sex risk behaviors among heterosexual methamphetamine users: literature review from 2000 to present. Curr Drug Abuse Rev. 2008;1(3):292-296.

3. United Nations Office on Drugs and Crime (UNODC). World Drug Report 2010. New York: United Nations; 2010. Available from: http://www.unodc.org/unodc/en/data-and-analysis/WDR-2010.html. Accessed June 30, 2011.

4. Wu LT. Substance abuse and rehabilitation: responding to the global burden of diseases attributable to substance abuse. Subst Abuse Rehabil. 2010;1:5-11.

5. Reference Group to the United Nations on HIV and Injecting Drug Use. The global epidemiology of methamphetamine injection: a review of the evidence on use and associations with HIV and other harm. Sydney, Australia: National Drug and Alcohol Research Centre, University of New South Wales; 2007.

6. Substance Abuse and Mental Health Services Administration. The DASIS report: Primary methamphetamine/amphetamine treatment admissions, 1992-2002. Rockville, MD: Office of Applied Studies, Substance Abuse, and Mental Health Services Administration; 2004.

7. Substance Abuse and Mental Health Services Administration. Results from the 2009 National Survey on Drug Use and Health: Mental Health Findings. NSDUH Series H-39, HHS Publication No. SMA 10-4609. Rockville, MD: Office of Applied Studies, Substance Abuse, and Mental Health Services Administration; 2010.

8. Rondinelli AJ, Ouellet LJ, Strathdee SA, et al. Young adult injection drug users in the United States continue to practice HIV risk behaviors. Drug Alcohol Depend. 2009;104(1-2):167-174.

9. Darke S, Kaye S, McKetin R, Duflou J. Major physical and psychological harms of methamphetamine use. Drug Alcohol Rev. 2008;27(3): 253-262.

10. Darke S, Hall W. Levels and correlates of polydrug use among heroin users and regular amphetamine users. Drug Alcohol Depend. 1995;39(3):231-235.

11. Wu LT, Woody GE, Yang C, Blazer DG. How do prescription opioid users differ from users of heroin or other drugs in psychopathology: results from the National Epidemiologic Survey on Alcohol and Related Conditions. J Addict Med. 2011;5(1):28-35.

12. Williamson S, Gossop M, Powis B, Griffiths P, Fountain J, Strang J. Adverse effects of stimulant drugs in a community sample of drug users. Drug Alcohol Depend. 1997;44(2-3):87-94. 
13. Inglez-Dias A, Hahn JA, Lum PJ, Evans J, Davidson P, Page-Shafer K Trends in methamphetamine use in young injection drug users in San Francisco from 1998 to 2004: the UFO Study. Drug Alcohol Rev. 2008; 27(3):286-291.

14. Fairbairn N, Kerr T, Buxton JA, Li K, Montaner JS, Wood E. Increasing use and associated harms of crystal methamphetamine injection in a Canadian setting. Drug Alcohol Depend. 2007;88(2-3):313-316.

15. McKetin R, Kelly E, McLaren J, Proudfoot H. Impaired physical health among methamphetamine users in comparison with the general population: the role of methamphetamine dependence and opioid use. Drug Alcohol Rev. 2008;27(5):482-489.

16. Mooney L, Glasner-Edwards S, Rawson RA, Ling W. Medical effects of methamphetamine use. In: Roll JM, Rawson RA, Ling W, editors. Methamphetamine addiction: from basic science to treatment New York: The Guilford Press; 2009.

17. Darke S, Torok M, Kaye S, Duflou J. Cardiovascular disease risk factors and symptoms among regular psychostimulant users. Drug Alcohol Rev. 2010;29(4):371-377.

18. Yeo K-K, Wijetunga $\mathrm{M}$, Ito $\mathrm{H}$, et al. The association of methamphetamine use and cardiomyopathy in young patients. Am J Med. 2007;120(2):165-171.

19. Molitor F, Truax SR, Ruiz JD, Sun RK. Association of methamphetamine use during sex with risky sexual behaviors and HIV infection among non-injection drug users. West J Med. 1998;168(2): 93-97.

20. Darke S, Ross J, Cohen J, Hando J, Hall W. Injecting and sexual risk-taking behaviour among regular amphetamine users. AIDS Care. 1995;7(1):19-26.

21. Dalmau A, Bergman B, Brismar B. Psychotic disorders among inpatients with abuse of cannabis, amphetamine and opiates. Do dopaminergic stimulants facilitate psychiatric illness? Eur Psychiatry. 1999;14(7): 366-371

22. Flaum M, Schultz SK. When does amphetamine-induced psychosis become schizophrenia? Am J Psychiatry. 1996;153(6):812-815.

23. McKetin R, McLaren J, Lubman DI, Hides L. The prevalence of psychotic symptoms among methamphetamine users. Addiction. 2006; 101(10):1473-1478.

24. Zweben JE, Cohen JB, Christian D, et al. Psychiatric symptoms in methamphetamine users. Am J Addict. 2004;13(2):181-190.

25. Baskin-Sommers A, Sommers I. Methamphetamine use and violence among young adults. J Crim Justice. 2006;34(6):661-674.

26. Tyner EA, Fremouw WJ. The relation of methamphetamine use and violence: a critical review. Aggress Violent Behav. 2008;13(4): 285-297.

27. Gunn AK, Rickwood DJ. The effect of amphetamine type stimulants on psychopathology, aggression and cognitive function among clients within a drug therapeutic community. Ment Health Subst Use. 2009;2(2):120-129.

28. Glasner-Edwards S, Mooney LJ, Marinelli-Casey P, et al. Anxiety disorders among methamphetamine dependent adults: association with post-treatment functioning. Am J Addict. 2010;19(5):385-390.

29. Glasner-Edwards S, Mooney LJ, Marinelli-Casey P, Hillhouse M, Ang A, Rawson R. Risk factors for suicide attempts in methamphetaminedependent patients. Am J Addict. 2008;17(1):24-27.

30. Ling W. Buprenorphine for opioid dependence. Expert Rev Neurother. 2009;9(5):609-616.

31. Metzger DS, Woody GE, O'Brien CP. Drug treatment as HIV prevention: a research update. J Acquir Immune Defic Syndr. 2010; 55(Suppl 1):S32-S36.

32. Ling W, Jacobs P, Hillhouse M, et al. From research to the real world: buprenorphine in the decade of the Clinical Trials Network. J Subst Abuse Treat. 2010;38(Suppl 1):S53-S60.

33. Tai B, Sparenborg S, Liu D, Straus M. The National Drug Abuse Treatment Clinical Trials Network: forging a partnership between research knowledge and community practice. Subst Abuse Rehabil. 2011;2:21-28.
34. Ling W, Amass L, Shoptaw S, et al. A multi-center randomized trial of buprenorphine-naloxone versus clonidine for opioid detoxification: findings from the National Institute on Drug Abuse Clinical Trials Network. Addiction. 2005;100(8):1090-1100

35. Wu LT, Ling W, Burchett B, Blazer DG, Shostak J, Woody GE. Gender and racial/ethnic differences in addiction severity, HIV risk, and quality of life among adults in opioid detoxification: results from the National Drug Abuse Treatment Clinical Trials Network. Subst Abuse Rehabil. 2010;1: $13-22$

36. Amass L, Ling W, Freese TE, et al. Bringing buprenorphine-naloxone detoxification to community treatment providers: the NIDA Clinical Trials Network field experience. Am J Addict. 2004;13(Suppl 1): S42-S66.

37. Ling W, Hillhouse M, Domier C, et al. Buprenorphine tapering schedule and illicit opioid use. Addiction. 2009;104(2):256-265.

38. McGahan PLGJ, Parante R, McLellan AT. Composite Scores from the Addiction Severity Index. Washington, DC: National Institute on Drug Abuse Project DA02554 and the Veterans Administration; 1982.

39. McLellan AT, Luborsky L, Cacciola J, et al. New data from the addiction severity index. Reliability and validity in three centers. J Nerv Ment Dis. 1985;173(7):412-423.

40. SAS Institute. SAS version 9.2. Cary, NC: SAS Institute; 2010.

41. Substance Abuse and Mental Health Services Administration, Office of Applied Studies. Treatment Episode Data Set (TEDS) Highlights - 2007 National Admissions to Substance Abuse Treatment Services. OAS Series S-45, HHS PublicationNo.(SMA)09-4360. Rockville, MD: Substance Abuse and Mental Health Services Administration; 2009.

42. Wu LT, Blazer DG, Patkar AA, Stitzer ML, Wakim PG, Brooner RK. Heterogeneity of stimulant dependence: a national drug abuse treatment clinical trials network study. Am J Addict. 2009;18(3):206-218.

43. Strathdee SA, Case P, Lozada R, et al. The color of meth: is it related to adverse health outcomes? An exploratory study in Tijuana, Mexico. Am J Addict. 2008;17(2):111-115.

44. Kerr T, Wood E, Grafstein E, et al. High rates of primary care and emergency department use among injection drug users in Vancouver. J Public Health. 2005;27(1):62-66.

45. Hendrickson RG, Cloutier R, McConnell KJ. Methamphetaminerelated emergency department utilization and cost. Acad Emerg Med. 2008;15(1):23-31.

46. Cohen AL, Shuler C, McAllister S, et al. Methamphetamine use and methicillin-resistant Staphylococcus aureus skin infections. Emerg Infect Dis. 2007;13(11):1707-1713.

47. Cook HA, Furuya EY, Larson E, Vasquez G, Lowy FD. Heterosexual transmission of community-associated methicillin-resistant Staphylococcus aureus. Clin Infect Dis. 2007;44(3):410-413.

48. Torbenson M, Kannangai R, Astemborski J, Strathdee SA, Vlahov D, Thomas DL. High prevalence of occult hepatitis B in Baltimore injection drug users. Hepatology. 2004;39(1):51-57.

49. Lee WM. Hepatitis B virus infection. N Engl J Med. 1997;337(24) 1733-1745.

50. Vogt TM, Perz JF, Van Houten CK Jr, et al. An outbreak of hepatitis B virus infection among methamphetamine injectors: the role of sharing injection drug equipment. Addiction. 2006;101(5):726-730.

51. Hutin YJ, Sabin KM, Hutwagner LC, et al. Multiple modes of hepatitis A virus transmission among methamphetamine users. Am J Epidemiol. 2000;152(2):186-192.

52. Douglas FG, Kafilmout KJ, Patt NL. Foreign particle embolism in drug addicts: respiratory pathophysiology. Ann Intern Med. 1971;75(6): 865-880.

53. Devlin RJ, Henry JA. Clinical review: major consequences of illicit drug consumption. Crit Care. 2008;12(1):202.

54. Conway KP, Compton W, Stinson FS, Grant BF. Lifetime comorbidity of DSM-IV mood and anxiety disorders and specific drug use disorders: results from the National Epidemiologic Survey on Alcohol and Related Conditions. J Clin Psychiatry. 2006;67(2):247-257. 
55. Cruickshank CC, Dyer KR. A review of the clinical pharmacology of methamphetamine. Addiction. 2009;104(7):1085-1099.

56. Sommers I, Baskin D, Baskin-Sommers A. Methamphetamine use among young adults: health and social consequences. Addict Behav. 2006;31(8):1469-1476.
57. Bell BP, Shapiro CN, Alter MJ, et al. The diverse patterns of hepatitis A epidemiology in the United States - implications for vaccination strategies. J Infect Dis. 1998;178(9):1579-1584.

\section{Publish your work in this journal}

Substance Abuse and Rehabilitation is an international, peer-reviewed, open access journal publishing original research, case reports, editorials, reviews and commentaries on all areas of addiction and substance abuse and options for treatment and rehabilitation. The manuscript management system is completely online and includes a very quick and fair peer-review system. Visit http://www.dovepress.com/testimonials. php to read real quotes from published authors.

Submit your manuscript here: http://www.dovepress.com/substance abuse-and-rehabilitation-journal 